\title{
El problema de la identidad en los protagonistas de Vuelo del cisne, de Rosario Ferré.
}

\section{The identity problem of the protagonists of Vuelo del cisne, by Rosario Ferré.}

\author{
Jinsol Choi \\ Universidad Nacional de Seúl (COREA DEL SUR) \\ CE: marisolchoi0813@gmail.com ID ORCID: 0000-0002-7308-9347
}

DOI: $10.32870 /$ sincronia.axxiii.n76.26b19

$\mathrm{BY} \cdot \mathrm{NC}$

Esta obra está bajo una Licencia Creative Commons Atribución-NoComercial 4.0 Internacional

Recibido: $25 / 03 / 2019$

Revisado: 23/04/2019

Aprobado: 20/05/2019

\section{RESUMEN}

La vida de Anna Pavlova, bailarina legendaria de Rusia, se reconfigura en la novela de Rosario Ferré, Vuelo del cisne. La novela cruza el año 1917, cuando se le entrega la ciudadanía estadounidense a Puerto Rico. Su cambio de identidad nacional es observado por la compañía de ballet rusa, que también pasa por la época de la Revolución en el mismo año. Gracias a la configuración de la narradora-personaje como extranjera y observadora, la novela permite ver las crisis de identidad por la parte de los puertorriqueños así como de la compañía de ballet. El objetivo de este trabajo es observar y analizar cómo se representa el amor entre los dos personajes, Niura Póliakoff y Diamantino Márquez. Ambos se dedican al arte y son idealistas; aquella, devota de la salvación de las almas y este, de la liberación de Puerto Rico dependiente de Estados Unidos. La historia de amor recuerda el discurso nacionalista de América Latina, una corriente persistente desde el siglo XIX, según Doris Sommer. Sin embargo, la novela no critica la ideología nacionalista. Veremos cómo se configura a la pareja para representar el discurso convencional del nacionalismo y, al mismo tiempo, cómo es criticado por la narradora-personaje, que puede observar sus contradicciones. 
Palabras clave: Identidad nacional. Nacionalismo. Amor y Patria.

\begin{abstract}
:
The life of legendary ballerina, Anna Pavlova, is fictionalized in Vuelo del cisne written by Rosario Ferré. The novel is majorly depicts the year of 1917 when the U.S. citizenship was granted to Puerto Rican people. This change of the national identity is observed by the ballet company from Russia, where the Revolution broke out in the same year. By setting the narrator as foreign to the Puerto Rico, the novel reveals the identity crisis of both Puerto Rico and the Russian ballet company. This article aims to observe and analyze how the love of two main characters is represented. The two protagonists, Niura Póliakoff and Diamantino Márquez, are dedicated to art and idealism; Madame is devoted to saving souls through art and Diamantino is struggling to realize the Independence of Puerto Rican nation from U.S. regime. The love story recalls the Latinamerican nationalist discourse, which is one of the persistent tendencies from the nineteenth century, according to Doris Sommer. However, the main stance of the novel is the criticism towards the nationalism. We will see how the couple is rendered in order to represent the conventions of Latinamerican nationalist discourse and, at the same time, how the couple is criticized by the narrator, who is also a character inside the novel, who observes the contradictions of the main characters.
\end{abstract}

Keywords: National identity. Nationalism. Love and Nation.

\title{
1. Introducción
}

Vuelo del cisne tiene como referencia histórica la visita de Anna Pavlova en Puerto Rico. La primera bailarina de la Escuela Imperial del Teatro Marínsky era famosa y había realizado varias giras mundiales. ${ }^{1}$ En el año de 1917, montó una función de ballet como confirma la memoria de Juan Tizol (Ledée, 1993).

\footnotetext{
${ }^{1}$ Existe una biografía de Anna Pavlova escrita por André Olivéroff, bailarín de la compañía de Pavlova, Flight of the Swan, cuyo título lo tomó igual Rosario Ferré para su novela. (Postlethwaite, 2001a; Postlethwaite, 2001b).
} 
Salvo su espectáculo en la isla, las aventuras en la novela son producto de la imaginación de Ferré. La protagonista, Niura Póliakoff, está configurada en función de la bailarina legendaria. No es difícil identificar a Niura con Anna Pavlova, ya que la mayoría de los detalles del carácter del personaje coincide con la biografía real. ${ }^{2}$ Su vida transcurre durante una época conflictiva por la Primera Guerra Mundial, la Revolución rusa y, particularmente en América Latina, por las revoluciones independentistas y las guerras civiles. Alejo Carpentier había escrito La consagración de la primavera, donde aparece también una bailarina rusa que llega a Cuba y se menciona a Pavlova varias veces, recordando su inspiración en la configuración del personaje (Jansen, 1982, pp. 599-600). La novela del presente trabajo, Vuelo del cisne, registra la historia de la artista verosímilmente, insertando la isla de manera intencional dentro de la trayectoria de la gira. ${ }^{3}$

La novela está narrada por una rusa cuya nacionalidad caduca por la revolución bolchevique. La narradora-personaje define a los miembros de la compañía rusa de ballet como "unos parias, sin país y sin ciudadanía. Escombros de un naufragio, astillas a merced de las olas" (Ferré, 2002, p. 38, citaremos por esta edición). Estos personajes llegan a Puerto Rico durante su gira por Sudamérica y se detienen durante unos seis meses a la espera de una nueva nacionalidad. Para la compañía, Puerto Rico es un limbo porque no pertenece a ningún país en ese momento a causa del cambio político por la Revolución rusa. Y también la isla pasa el cambio drástico de la identidad nacional.

El año de 1917 en que se ubican los hechos de la novela es significativo para Puerto Rico por la concesión de la ciudadanía estadounidense, y el hecho de que Ferré lo haya aludido en la mayoría de sus obras insinúa que este año es crucial en cuanto a la identidad y a la memoria colectiva de Puerto Rico. Además, la Revolución rusa concurre en el mismo año. Se sobreponen ambas situaciones parecidas, lo cual hace que la estadía de la compañía de ballet no sea una mera visita temporal sino una situación significativa ante la decisión acerca de la pertenencia a una nación.

\footnotetext{
${ }^{2}$ El nombre de Niura también era el nombre infantil de Pavlova, según consta en una novela biográfica de la bailarina, Dancing Star: The Story of Anna Pavlova, de Gladys Malvern (2016).

${ }^{3}$ El interés que tiene Ferré por Pavlova, especialmente en cuanto a su gira por América Latina, habría podido inspirarse en la novela de Carpentier, que se publicó en 1978. Ferré fue ávida lectora de Carpentier, cuya influencia absorbió para su propia creación (Martínez, 2018).
} 
En este trabajo, observaremos la relación entre Diamantino Márquez y Niura Póliakoff denominada como Madame. La relación está descrita por Masha, la narradora-personaje. La novela registra la evolución de la pareja pero nos importan los primeros momentos porque en ellos se manifiesta el simbolismo del amor. El suceso central del texto es el enamoramiento de la Madame seguido de la decepción y traición de Masha, que es su confidente. A Masha le toca asumir la realidad de que están en un nuevo país y, lo más importante, de que Madame, la primera bailarina y su ídolo, se está alejando de la compañía por haberse enamorado de un isleño.

El objetivo de este trabajo será revisar qué aspecto de la isla y del isleño atrae a Madame y la cambia en sus intereses, lo cual influye en la caracterización del personaje masculino. Antes, habrá que analizar la identidad percibida por la compañía de ballet para entender por qué Masha considera el enamoramiento de Madame como una traición. Su obsesión se basa en la identificación de Madame con la compañía, cuyo único mundo es el arte, lo cual motiva su traición contra Madame en el final de la novela. Por parte de Madame, la cuestión de la identidad también es determinante para su encuentro y enamoramiento con Diamantino; la relación de la pareja no se reduce a una mera aventura dentro de una isla tropical, sino que tiene el aspecto de camaradería ante el cambio de cada identidad nacional. Intentaremos verificar cómo se presenta la fusión entre el nacionalismo y el arte, representados respectivamente por Diamantino y Madame.

\section{La patria en el pasado y el origen del ser para los bailarines}

Al observar la isla en un principio, Masha no se impacta emocionalmente hasta que Madame se encuentra a Diamantino. A la compañía se le permite solo una temporada en Puerto Rico y la isla es meramente una escala de espera hasta conseguir la nueva nacionalidad, al mismo tiempo que montan funciones de ballet. Ya que Puerto Rico no se considera como su destino permanente, las primeras observaciones sobre la isla sirven de trasfondo para la configuración del espacio y no influyen en el cambio de los personajes. Aunque estaban detenidos, de todos modos, habrían podido seguir bailando hasta que consiguieran nuevos pasaportes y partieran a Sudamérica como estaba planeado. Así pues, en un primer momento, el encontrarse en Puerto Rico no parecía una 
situación insalvable ya que estaban de gira y dentro de un tiempo en que podían salir. Más bien, lo que perturba a la compañía es la noticia sobre la Revolución rusa:

Caminamos por la calle completamente mareados, como si el piso se ladera [sic] bajo nuestros pies. Molinari venía detrás de nosotros, igual que un cuervo en un velorio. Nuestro espíritu estaba en añicos, pero afortunadamente nuestra troupe seguía unida. Y nuestra fe en la Santa Madre Rusia y en nuestro arte estaba intacta.

Hicimos todo lo posible por mantener el ánimo en alto. Hablar sobre nuestra ciudad y sobre el pasado nos hacía sentir mejor; nos ayudaba a sobreponernos al miedo de que ahora ya no teníamos patria, de que separanos [sic] podía significaba [sic] perdernos en un mundo inhóspito. La compañía era nuestra familia y nos necesitábamos desesperadamente unos a otros. Hablar de Rusia, recordarla, era igual que afirmar su existencia. (pp. 39-40)

Como señala Laura-Eugenia Tudoras, la hora en que reconocen la pérdida de pertenencia es cuando la compañía se aferra a la memoria del pasado. Antes, el arte es el universo en el que creen que viven. Después de asumir la realidad de que ya no pertenecen a ningún país, las bailarinas rusas "consiguen envolverse en una patria interior, una patria emocional en la que consiguen que Rusia siga existiendo para ellas, con la sencillez de un acto performativo, con el simple hecho de hablar de ella" (Tudoras, 2017, p. 70).

Sin embargo, hay que destacar que la compañía es devota del arte como insiste Madame: "el ballet es una experiencia espiritual" (p. 32). Para la compañía, el ballet es una religión, una ideología a la que se deben entregar y unir como un mismo ser: "Así, el baile, su vocación y razón de ser, el eje que articula su identidad a nivel íntimo y personal, se convierte además en su nueva patria, en una identidad nacional" (Tudoras, 2017, p. 69). Su desempeño artístico se configura como un ritual religioso y Madame se posiciona como una santa venerada:

En los tiempos antiguos la devoción hacia los dioses, la felicidad o la tristeza se expresaban a través del cuerpo. El cuerpo era el arpa del espíritu, por medio del cual se alcanzaba la unión con la divinidad. Éramos todas solteras, a pesar de los apuestos jóvenes que siempre nos estaban esperando a la puerta trasera del teatro cuando terminábamos un 
recital. [...] A veces ayunábamos durante varios días para mantenernos delgadas y livianas sobre nuestros pies. El hambre nos limpiaba, nos purificaba de todo deseo. El dolor quería decir que estábamos trabajando duro, que estábamos haciendo las cosas bien. Una bailarina está dispuesta a soportar el dolor para que su arte trascienda lo mundano. Y en cada uno de estos empeños, imitábamos siempre a Madame. (p. 18)

La compañía no pertenece a ningún lugar particular porque su única pertenencia era el arte trascendental. ${ }^{4}$ El hecho de que el lugar de espera sea Puerto Rico no perturba a Masha de manera drástica al principio. Aunque se queda sorprendida, es prioritario mantenerse como discípula y bailarina de la Madame que identificarse con una cierta nacionalidad. ${ }^{5}$

Al perder la nacionalidad y a pesar de la conmoción creada, los personajes pueden mantenerse unidos al evocar el pasado. Después de enterarse de la noticia de la Revolución rusa, la secuencia que sigue es donde la madre de Madame cuenta una historia juvenil de su hija para calmarlas: "A menudo charlábamos sobre nuestras cosas y nos contábamos historias para entretenernos, y en Puerto Rico lo hacíamos aún más, para no volvernos locas" (p. 40). Saben manejar la confusión en cuanto al cambio de nacionalidad porque creen que dicho cambio no va a afectar su pertenencia a la compañía. De la misma manera, confrontan la crisis de sentirse desarraigadas y solitarias. Al enterarse de la muerte de Madame, Masha se resiste a cambiar: "convertirme en un fantasma, en una mujer sin patria, sin amor y sin recuerdos, abrazada a mi propia sombra" (p. 5). Opta por la misma forma de resistencia de la compañía en la época durante la espera en Puerto Rico, que es recordar el pasado y así comienza la novela.

\footnotetext{
${ }^{4}$ Tudoras $(2017$, p. 71$)$ cita el fragmento donde se muestra que la compañía piensa que su única pertenencia que le importa era el arte: "Nuestro hogar, dulce hogar se evapora; ya no se encuentra en ninguna parte. Sólo existe el escenario, donde uno se desnuda el alma todas las noches (...). La ventaja era que vivíamos sin ataduras de ninguna clase: no teníamos ni patria, ni pueblo, ni casa (...). Estábamos hechos de aire y de estrellas: pertenecíamos al universo y eso nos daba una gran tranquilidad". (Los cortes de la cita pertenecen al artículo).

${ }^{5}$ El paradero de Madame, que coincide casi con el de Anna Pavlova, evidencia que Madame no deja de moverse para seguir su arte. La gira incluye toda Europa y las Américas, que se agregan en la lista de los países que visita Pavlova en su gira; abarca Egipto, India, Asia del Este y Australia. Madame es una viajera a la que no le importa tener una nacionalidad fija. A este respecto, es interesante ver que Madame nace en Rusia, se arraiga en Reino Unido, sigue viajando por mundo y luego muere en La Haya durante una gira, datos del personaje que coinciden con la vida real de Pavlova (S/A, 2018; Allman, 2006, p. 57).
} 
Se muestra un contraste en la reacción de las bailarinas cuando surge la ocasión de ser despedidas de la compañía. El miedo de ser rechazadas es tan fuerte que induce a obsesión y muertes. Una vez, Madame rechaza a una bailarina por engordarse y por haber sido infiel con el marido de Madame, la bailarina se suicida desesperada, tirándose por la ventana. Además, cuando corren rumores de que Madame ha decidido irse de la compañía para huir con su amante Diamantino, Masha divulga el paradero del hombre y coadyuva involuntariamente a su muerte. El arte y la compañía son el único universo al que pertenecen los personajes y significa más que una patria.

\section{El comienzo del cambio}

Masha se siente amenazada al notar los cambios producidos por la estancia en Puerto Rico y piensa que la aparición de Diamantino Márquez alterará el orden de la compañía. Diamantino es un líder político que encabeza el movimiento independentista, lo cual atrae a Madame. Madame tenía muchos admiradores y pretendientes, pero la razón de dejarse seducir por Diamantino se relaciona con su activismo político.

Antes de encontrarse a Diamantino, el primer personaje puertorriqueño por el que se interesa Madame es un poeta nacionalista, Manuel Aljama. Madame lo ve recitar un poema lleno de emoción patriótica en una escuela y luego la policía lo atrapa porque está prohibido manifestar el nacionalismo bajo el régimen estadounidense. Al escuchar su poema, Masha confiesa que Madame y ella sienten una gran emoción: "hasta los pájaros en los árboles hicieron silencio para escucharlo. [...] Madame, no hablaba español, pero a ambas nos conmovió profundamente" (p. 62). El poeta independentista propicia un ambiente místico y sagrado que lo hace parecer como un profeta. Madame se configura también como una santa o gurú que piensa que su misión es salvar a los espíritus en el mundo a través del arte sublime: "esclavos de sus cuerpos, la carne los domina y su espíritu ya no puede volar. Intentaremos ayudarlos con nuestro baile" (p. 20). El poeta con su nacionalismo sagrado y la Madame con su arte trascendental, ambos quedan mistificados y puestos a la par para que se comuniquen y se conmuevan. 
El enamoramiento de Madame y Diamantino es posible porque Madame lo percibe como un artista y liberador, que irradia un ambiente sagrado igual que Aljama. En su primera aparición, la descripción de Diamantino lo distingue de los demás: "no iba vestido de etiqueta. Vestía una chaqueta de hilo blanco y llevaba una cinta de luto cosida a una de las mangas" (p. 71). Como su padre, que era Primer Ministro y luchaba contra España para la Independencia, Diamantino también encabeza el movimiento independentista contra Estados Unidos y "lo consideraban el heredero legítimo al trono en el cual se sienta hoy el Gobernador" (p. 85). La vestimenta de luto era para recordar la muerte de su padre que había ocurrido seis meses antes del primer encuentro entre Madame y Diamantino. Así pues, su traje significa su rebeldía para mostrar su denuncia de que la nación puertorriqueña está de luto por la llegada de Estados Unidos, así como la traición de la élite social.

Esta alusión que une a Diamantino en el nivel místico que se había formado antes por la parte de Madame y Manuel Aljama permite que la protagonista sienta una compasión que luego facilitará el enamoramiento. Por otra parte, la alusión a la muerte se agrega para la unión entre los tres personajes. La obra que hace a la bailarina célebre internacionalmente es La muerte de cisne, la cual Madame baila en la fiesta donde conoce a Diamantino. Esta obra es una elegía por la agonía de su patria, Rusia, así como, un llanto por su pérdida: "Europa se estaba desangrando, pero la compasión y el amor todavía eran posibles; ese era el mensaje de Madame. La muerte de cisne, el ballet que la hizo famosa por todo el mundo, era un oración por la paz. Nuestro amado San Petersburgo era el cisne, desgarrado por la guerra civil" (p. 24). Justo antes de aparecer Diamantino, Madame pregunta a Aljama el título del poema que había recitado y el personaje responde: "se llama Último réquiem y es un poema sobre la muerte y la resurrección de la patria" (p. 70). Durante esa conversación, "Madame sintió un escalofrío, y se abrigó más estrechamente su chal” (p. 70), y justo después, Diamantino aparece en la escena vestido de luto. La emoción producida por el símbolo de la muerte fluye alrededor de los tres personajes. Así pues, el enamorarse de Diamantino no es un suceso que ocurra drásticamente, sino la cima de imágenes sagradas y trágicas, lo cual es posible porque Diamantino está configurado en el mismo nivel de mistificación que Madame. 
Por otro lado, Diamantino rivaliza con el poeta nacionalista para conseguir el interés de Madame. Diamantino se presenta a sí mismo como "periodista y poeta" (p. 72), y enumera sus conocimientos sobre el arte y la literatura, lo cual "la ponía mal, dijo, le daba una migraña terrible. Diamantino no se desanimó ante su falta de interés, sin embargo. Como todos los jóvenes intelectuales de su edad, quería pavonearse de sus conocimientos frente a Madame" (p. 72). Madame todavía se encuentra interesada por Aljama mencionando la conversación que acababa de tener, pero Diamantino luego divulga que Aljama había traicionado su propia ideología, de lo cual deviene su desmitificación:

“¿Sabe por qué se Ilama Estrella?”. Madame dijo que no sabía. "Por la estrella de nuestra bandera. Como los americanos la han prohibido y nadie puede tenerla en casa, el poeta se la puso de nombre a la niña. ¿No le parece divertido?”, dijo con una sonrisa irónica. [...] “Alijama ha publicado versos muy buenos", respondió el joven. "Pero es un león mellado". Y le contó cómo, luego de jurar que nunca adoptaría la ciudadanía enemiga, había tenido que hacerse ciudadano norteamericano antes de viajar a los Estados Unidos para la operación de la pierna. "Se operó en el hospital Mount Sinai, en Nueva York, porque desconfiaba de los médicos en la isla". (pp. 75-76)

Con la denuncia hacia Aljama por traidor, Diamantino toma la delantera en conseguir la atención de Madame y mantiene su imagen de profeta ante ella, observados por Masha a ocultas:

La voz le temblaba de emoción y hacía gestos dramáticos con las manos. Un manojo de pelo negro y rebelde le caía desordenado sobre la frente. Me hizo pensar en un cuadro que había visto una vez en la catedral de San Petersburgo, donde un Cristo enfurecido sacaba a los mercaderes del Templo a latigazos. Diamantino no era más que un imberbe, un niño malcriado y consentido, y sin embargo allí estaba Madame, la estrella del Ballet Imperial del Maríinski, escuchando lo que decía embelesada y con la boca abierta. (p. 76)

La primera bailarina rusa es figura mesiánica admirada por sus seguidores y todo lo relacionado con ella se considera como fetiche sagrado: 
Hubiésemos podido matar por un jirón de tela de su falda, por la cinta de una de sus zapatillas. Nos disputábamos cada recuerdo suyo con las uñas. Una vez que Madame bailó la escena de la locura en Giselle, por ejemplo, y se arrancó un mechón de pelos de la cabeza, las muchachas lo buscaron por el escenario durante horas una vez terminada la obra. (pp. 29-30)

La comunicación que logra Diamantino con Madame se hace posible porque había podido parecer espiritual como ella y emanaba misticismo. De esta manera, para Madame, Diamantino no solo es un joven que tiene veinte años menos que ella sino que se convierte en la inspiración de su vida.

Diamantino es un personaje que representa la unión entre el nacionalismo con el arte. El ambiente místico se logra por su preocupación sobre el cambio de nacionalidad y de la ideología. Cabe destacar que este personaje se involucra en el arte. A pesar de su origen en la alta sociedad, al apoyar la independencia contra la mayoría de la élite social lo distingue como rebelde. Además, su interés y participación en el arte lo hace parecer un bohemio que aspira seguir en ese ambiente. La segunda aparición de Diamantino es dramática porque pide participar en la orquesta para la compañía de ballet, lo cual Masha califica como un hecho terrible:

Madame súbitamente le hizo una seña a Smallens, y la orquesta se detuvo en seco, a mitad de un compás. Yo estaba a la derecha de Madame en el escenario, y vi sus ojos relucir en la oscuridad. Alguien estaba de pie, al fondo del teatro. Sólo podíamos ver su silueta; iba vestido de hilo y llevaba una banda de luto en el brazo. El corazón me dio un vuelco y se me atravesó en la garganta: era Diamantino Márquez. Sonreía ampliamente, y en la mano cargaba el maletín de su violín. [...] En cuanto Madame escuchó la melodía de Diamantino se transformó en otra persona. Yo nunca la había visto bailar así, su cuerpo un látigo que se rizaba y desenrizaba frenético, su mirada un ruego mudo que sólo podía descifrarse en relación a otra mirada. Se había olvidado por completo de nosotros y de nuestra misión sagrada. Bajo los ojos apasionados de Diamantino, aquella tarde se consumió en el escenario como una zarza ardiente. (pp. 100-101) 
Madame que baila al compás de la música de Diamantino marca el comienzo de la crisis para Masha. La obra es La Baccanale que, según la narradora, es un acto "demasiado caótico. En él se reafirma la supremacía de la pasión sobre el sabio consejo de la razón" (p. 104). Al principio de la participación de Diamantino en la orquesta, está bajo el escenario donde baila Madame pero cien páginas después, sube al escenario para bailar a dueto con Madame La Baccanale, sustituyendo a un bailarín enfermo. Después de La Baccanale, desaparece la pareja para unirse a la guerrilla. El amor y la locura combinados transforman a Madame y están simbolizados en la obra que tiene su origen de la leyenda de Dionisio y Ariadna:

Se trata de la leyenda de Dionisio y Ariadna, princesa de Creta, que es abandonada por Teseo en la isla de Naxos. Dionisio, el dios del vino, acude a rescatar a Ariadna, pero es devorado por las bacantes -sacerdotisas sagradas de los ritos de la fertilidad y de la danza- en el transcurso de una orgía monumental. (p. 104)

La versatilidad de poeta, violinista y hasta bailarín muestra la aspiración artística del personaje, por la cual el romance de la pareja cobra una sensación fuera de lo corriente. Hasta su final es dramático porque asesinan a Diamantino literalmente encima del escenario en la fiesta de carnaval, donde Madame iba a bailar de nuevo La Baccanale, la obra que simbolizaba el amor de la pareja. El nacionalismo y la devoción al arte, aspectos del carácter de Diamantino, funcionan para enardecer su amor y justifican la fuga de Madame para unirse a la guerrilla de Diamantino, así como su nueva devoción de bailar para el pueblo, no para la alta sociedad.

\section{La nación en la metáfora de la familia y el nacionalismo de Puerto Rico}

Doris Sommer revisa las ficciones latinoamericanas del siglo XIX, con el fin de comprobar que hay un enlace entre el nacionalismo y la novela romántica. Sommer (1991, pp. 6-7 y 13-19) afirma que las novelas románticas representan el amor y la pasión como un estado natural y, luego, como una amalgama para controlar los conflictos bajo el nombre de una nación. Según Sommer, lo destacable es que el amor hacia una persona se relaciona con el amor a la patria. Aquí, el amor nace siempre a 
través de la relación heterosexual y se manifiesta públicamente en la literatura romántica, donde también coincide el surgimiento del nacionalismo. ${ }^{6}$ El amor y el matrimonio que vencen los obstáculos funcionan como metáfora de la nación que unifica sin importar las diferencias, lo cual, sin embargo, no significa la igualdad. La élite social latinoamericana consideró al público como vehículo de su ideología pero no pensó en compartir con ellos los privilegios aristocráticos que heredaba (Sommer, 1991, pp. 13-14 y 48). La crítica estadounidense denomina esta gama de novelas national romance, ${ }^{7}$ en las que se encuentra la estrategia mayormente de la élite social justo después de la independencia con el fin de consolidar el concepto de nación de manera pacífica.

Aunque se debe considerar la singularidad del nacionalismo puertorriqueño, que nunca alcanzó su independencia, podríamos examinarlo en función de la corriente común que señala Sommer. Diamantino comenta sobre la historia de Puerto Rico: "Somos la última vagoneta del tren; la única colonia latinoamericana que no llegó nunca a ser independiente. Las tropas norteamericanas se quedaron con nosotros al final de la guerra hispanoamericana, y en el 98, pasamos a ser botín de guerra" (p. 76). Los national romances que señala Sommer son creaciones después de la independencia, a mediados del XIX. Pero Puerto Rico nunca se independizó y el nacionalismo abordado en la novela ocurre a comienzos del siglo XX.

Sin embargo, como indica Marisel Moreno (2012, p. 8), el discurso nacionalista puertorriqueño comparte afinidades con la tendencia general acerca del nacionalismo a través de las narrativas románticas. La tendencia literaria que toma Moreno acerca del nacionalismo abarca mayormente los años de la década de 1930, cuya ideología y constitución en función de género, raza y clase económica coinciden con el nacionalismo generalizado en la explicación de Sommer (2012, pp. 16-17). Por lo tanto, en la novela de Ferré, el amorío en los conflictos acerca de la

\footnotetext{
${ }^{6}$ Sommer examina y combina las teorías de Foucault y de Anderson para la observación mencionada arriba (1991, p. 33).

7 La palabra 'romance' en español significa un género de literatura: "novela o libro de caballerías, en prosa o en verso" s.v. DRAE. Sommer $(1991$, p. 5) define la palabra 'romance' como sigue: "By romance here I mean a cross between our contemporary use of the word as a love story and a nineteenth-century use that distinguished the genre as more boldly allegorical than the novel". Utilizaremos el término national romance en inglés para indicar las novelas románticas del estudio de Sommer.
} 
identidad nacional no es un asunto privado de un personaje sino que alude a la confabulación entre las novelas románticas y al nacionalismo. Se debe reconocer que la novela no es un national romance sino que, más bien, alude al género con la configuración de los personajes, cuyo motivo no es para elogiar a la patria sino para parodiar y criticar la ideología de dicho género.

Se puede comprobar que Ferré se sublevó contra la literaria canónica de Puerto Rico cuya ideología era casi igual que el nacionalismo del siglo XIX. Ferré mantiene una crítica hacia el aspecto androcéntrico del nacionalismo puertorriqueño, lo cual se deja ver en Maldito amor y La casa de la laguna. Según Lidia Santos (2003, pp. 953-956), Ferré utiliza el melodrama de manera paródica para criticar. Esta manera es contraria a la intención de los nacionalistas del siglo XIX, que procuraban consolidar una nación bajo el mando de la élite social. Así pues, la historia de amor de Vuelo del cisne no sigue la misma ideología del national romance sino que se posiciona como objeto de observación y crítica (Moreno, 2012, p. 61; Murphy, 1997, p. 145; González, 2016, p. 169).

Podemos comprobar los referentes históricos que se relacionan con Diamantino en el estudio de Moreno. El nacionalismo puertorriqueño es la particularidad de su familia, como una metáfora de la nación puertorriqueña, unida y sumisa bajo la élite social y contra el colonialismo de España y de Estados Unidos. ${ }^{8}$ Dentro de su análisis, destaca el comentario sobre la variación del nacionalismo puertorriqueño en los años treinta, porque la propaganda se vuelve trascendental para "cultivar el 'carácter espiritual' de la nación". ${ }^{9}$ La propaganda de 1930 enfatiza que la nación puertorriqueña exalta su alma para mantenerse unida como familia y para asumir una posición contra el consumismo, otra forma de la influencia de Estados Unidos.

La llegada de la bailarina que tiene como misión la liberación del alma del pueblo y su romance con un guerrillero que es, al mismo tiempo, poeta en los tiempos de conflicto puede ser una muestra de la tendencia del nacionalismo en Puerto Rico. Tendríamos una imagen de cómo

\footnotetext{
${ }^{8}$ Moreno cita a Djelal Kadir, quien dijo que la historia en Latinoamérica se representa en el tropo de la familia. Su idea tiene el riesgo de reducir la literatura latinoamericana a un cierto modelo limitado, pero en cuanto al foco temático de la obra de Ferré, que es la historia de la familia, esta indicación tiene validez (Kadir citado por Moreno, 2012, p. 8).

${ }^{9}$ La traducción es mía. El texto original dice lo siguiente: "to cultivate the 'spiritual character' of the nation" (Rivera citado por Moreno, 2012, p. 38).
} 
habría sido el estado exaltado del nacionalismo después de la anexión de Puerto Rico a Estados Unidos. Según Quintero Rivera, los sujetos del nacionalismo de los treinta pertenecen a la segunda generación de las haciendas cañeras, que pierde los privilegios que iba a heredar de sus padres, a causa de la llegada de los Estados Unidos. Luego, se convierte en el estrato burgués, que no es igual que la aristocracia basada en la producción azucarera:

This second generation, born at a time when the social structure of the haciendas was beginning to collapse, and politically-born when their class had lost its political and economic hegemony, therefore occupying a secondary position in the social hierarchy, developed a more radical and change- driven ideology. [Esta segunda generación, que había nacido en la época en que empezaba a decaer la estructura social y política, surge cuando su clase había perdido su hegemonía política y económica dando como resultado que deba ocupar una segunda posición en la jerarquía social, desarrolló una ideología más radical y orientada a cambios -La traducción es mía-]. (Rivera citado por Moreno, 2012, p. 31).

En el texto, Diamantino Márquez es hijo de un hacendado de tabaco y aristócrata, pero su familia se exilia por la ocupación estadounidense. Su padre se dedica a la lucha independentista contra España, lo cual coincide con la descripción sobre los hacendados de fines del siglo XIX, anteriores a la segunda generación a la que pertenece Diamantino. Al perder la hegemonía, Diamantino se hace periodista y poeta, profesiones que no son propias de los aristócratas. Además, el personaje muere en el año 1917 pero tenía veinte años. Aunque la variación trascendental del nacionalismo que destaca Moreno (2012, p. 16) se evidencia a partir de 1930, los escritores y pensadores de "la generación del treinta", nacen en la misma época que Diamantino y comparten ideologías parecidas. Podríamos considerar a Diamantino como un personaje que tiene puntos en común con la generación del treinta, pero que llega a morir joven sin realizar sus aspiraciones. Así pues, la historia de Diamantino y de Madame sería una aventura construida con contextos ideológicos de la época de 1930 con el fin de hacer una crítica hacia la evolución de la sociedad isleña. 


\section{Conclusión}

La novela Vuelo del cisne no es un national romance cuyo fin sería unir al pueblo bajo el título de nación, a pesar de su condición dependiente de los Estados Unidos. Esto se debe a la crítica de Masha, narradora-personaje y también a la ideología de la autora de la novela. El hecho de que la narradora-personaje y focalizadora principal sea extranjera resulta significativo. La configuración opta por una narradora-personaje extranjera para distanciarse en la observación sobre Puerto Rico. Su lugar de origen es Rusia en la época de la Revolución y este detalle aporta un sentido a la observación o crítica particular que se muestra dentro de la novela. Por otro lado, el comentario de la narradora-personaje sobre la isla no podría ser auténticamente extranjero, ya que la autora es puertorriqueña ni se puede definir cómo es ser extranjero -en este caso, ruso- tan fácilmente. Es difícil justificar que las sorpresas o atenciones dirigidas hacia la isla sean las que probablemente se le podrían ocurrir a un extranjero.

En la novela se muestra el conflicto entre clases, el cual sirve mayormente como un obstáculo que dificulta el que Masha empatice con la pareja. Masha ve aspectos del personaje revolucionario y de la bailarina legendaria más allá del ambiente místico y piensa que la pareja es hipócrita por pretender participar en la agonía del pueblo ya que no pertenece a su clase, la clase obrera. Masha piensa: "el nombre le iba bien. Tenía la ropa estrujada y los zapatos sucios, pero los botones de pasador de su camisa llevaban diamantes incrustados, lo cual no lo identificaba con la clase obrera" (p. 72). Se insinúa desde el principio la duda de Masha hacia Diamantino sobre la intención verdadera de acercarse a Madame y sobre la autenticidad de su devoción ideológica.

Masha sigue manteniendo distancia con el amante y pretende persuadir a Madame para que se concentre en la compañía y en el arte como antes, lo cual se convierte en su obsesión. También se siente traicionada porque reconoce la diferencia de clase que siempre ha habido entre ellas. Sin sueldo ni compensación, Masha siempre ha sido como sirvienta. O según indica ella misma: "vírgenes vestales dedicadas a las glorias espirituales del ballet" (p. 208), al servicio de Madame, la bailarina del Zar: 
Yo había sacrificado mucho al irme de Rusia: Había traicionado la Revolución. Como miembro de la clase obrera yo tenía un futuro prometedor, mientras que a Madame, a pesar de ser hija de una lavadora, se le había identificado con la nobleza. Su interpretación de 'La muerte del cisne' era una metáfora de la agonía de la aristocracia, aunque ella quizá no se había dado cuenta de ello. (pp. 127-128)

Madame es el ídolo de Masha. Tiene esperanzas de parecerse a ella porque su maestra también viene de origen humilde; es bastarda de una lavandera violada. Masha también es víctima del abandono de la familia, del abuso sexual y de la violencia. Para ella, Madame es más que una maestra de ballet o artista legendaria: es la salvadora de su vida y el camino por el que aspira seguir: "[Juan] me decía su gansa porque yo siempre andaba corriendo detrás de Madame, que era el cisne" (p. 208). Las esperanzas que tenía Masha puestas en Madame se rompen con la desmitificación del personaje, porque Madame abandona el valor del arte, la promesa vital para la compañía, y porque Madame no tendría por qué empatizar con las jóvenes de origen humilde. Masha dice:

Para ese tiempo todavía era muy difícil que las jóvenes de clase media llegaran a ser bailarinas de ballet, y muchos de las estudiantes de la Escuela Imperial procedían de las familias más pobres de San Pertersburgo. [...] Nuestra veneración por Madame era tácitamente parte de nuestra lucha por estar al timón de nuestras propias vidas. (pp. 33-34)

Por lo tanto, el reconocimiento de Masha acerca de la distancia con Madame es abismal:

Madame vigilando su maletín de joyas con el rabillo del ojo mientras bailaba 'para el pueblo': por eso yo los despreciaba a todos. Ninguno de ellos sabía de veras lo que era ser bolchevique. Ser bolchevique quería decir un bastardo, un bárbaro. El bolchevique no tenía un centavo, se rascaba la crica en público, se tiraba pedos que llegaban al Asia y que apestaban a mil demonios. Ser bolchevique quería decir ser alguien como yo. (p. 145) 
A través de la novela, Masha juzga a la burguesía en Puerto Rico, que está a la par de la corrupción de Madame, desde la perspectiva de Masha, donde la discriminación y el conflicto entre las clases se sobreponen al caos del cambio de la nacionalidad de Puerto Rico.

\section{Referencias}

Allman, B. (2006). Dance of the Swan: A Story about Anna Pavlova. Minneapolis: Millbrook.

Ferré, R. (2002). Vuelo del cisne. New York: Vintage.

González, A. (2016). ' $R$ ' is for Rebel: Rosario Ferré (1938-2016). Review: Literature and Arts of the Americas, 49(1-2), 167-171.

Jansen, A. (1982). ¿Es La consagración de la primavera (1978) la obra maestra de Alejo Carpentier? En Actas del VII Congreso de la Asociación Internacional de Hispanistas (1980), (pp. 591-601). Roma: Bulzoni Editore.

Ledée, R. A. (1993). En busca de Juan Tizol. En Herencia Latina. Revista Musical Latinoamericana. Obtenido el 2 de enero de 2019 de http://www.herencialatina.com/Juan Tizol/Juan Tizol 2/Perfiles Juan Tizol.htm

Malvern, G. (2016). Dancing star: the story of Anna Pavlova. New York: Open Road Media.

Martínez, R. (2018, 27 de junio). Rosario Ferré: Papeles de pandora. Oculta Lit. Recuperado de https://www.ocultalit.com/narrativa/rosario-ferre-papeles-de-pandora/

Moreno, M. C. (2012). Family Matters: Puerto Rican Women Authors on the Island and the Mainland.

Charlottesville: University of Virginia.

Murphy, M. (1997). Rosario Ferré en el espejo: Defiance and Inversions. Hispanic Review, 65 (2), 145-157.

Postlethwaite, D. (2001a, 29 de julio). Roadies. The New York Times. Recuperado de https://www.nytimes.com/2001/07/29/books/roadies.html

Postlethwaite, D. (2001b, 29 de julio). The New York Times. 'Flight of the Swan': A Ballerina Stranded in Puerto Rico. En Puerto Rico Herald. Recuperado de http://www.puertoricoherald.org/issues/2001/vol5n31/SwanFerre-en.html

RAE (2018). Diccionario de la lengua española. Madrid: Espasa. Recuperado de https://dle.rae.es/?id=WdT7nIL 
S/A. (2018). Anna Pavlova. Dancer. Biography. Royal Opera House. Recuperado de http://www.roh.org.uk/people/anna-pavlova

Santos, L. (2003). Melodrama y nación en la narrativa femenina del Caribe contemporáneo. Revista Iberoamericana, 69(205), 953-968.

Sommer, D. (1991). Foundational Fictions: The National Romances of Latin America. Berkeley: University of California.

Tudoras, L.-E. (2017). Postmodernidad y espacios de identidad femenina en El vuelo del cisne de Rosario Ferré. Cincinnati Romance Review, (42), 67-79. 